\title{
"PRONTA PARA
}

\section{BRILHAR MUITO,}

AQUARIANA?":

O ETHOS

\section{DO DISCURSO \\ DE AUTOAJUDA}

\section{PARA ADOLESCENTES}

\author{
"¿LISTA PARA BRILLAR MUCHO, ACUARIANA?": \\ EL ETHOS DEL DISCURSO DE AUTOAYUDA PARA ADOLESCENTES
}

"READY TO SHINE A LOT, AQUARIAN?":

THE ETHOS IN THE SELF-HELP DISCOURSE FOR TEENAGERS

\author{
Marize Barros Rocha Aranha* \\ Cláuberson Correa Carvalho** \\ Universidade Federal do Maranhão
}

RESUMO Este artigo analisa a constituição do ethos do discurso de autoajuda para adolescentes sob a perspectiva da Análise do Discurso de linha francesa. Partimos de uma concepção de ethos fundamentada em Maingueneau (2008a, 2008b), que privilegia a análise do intradiscurso, isto é, os modos de dizer, as formas de construção textual, as balizas da superfície discursiva. O corpus compreende três edições publicadas pela revista Capricho. Os resultados apontam os efeitos de sentidos (empatia, espontaneidade, certeza, autoridade) estabelecidos no contrato de comunicação firmado por essa revista, percebendo como eles contribuem para a aproximação, por meio da leitura, entre enunciador jornalista e enunciatário adolescente.

PALAVRAS-CHAVE: discurso; ethos; contrato de comunicação.; enunciação.

RESUMEN: En este artículo se analiza la formación del ethos del discurso de autoayuda para adolescentes desde la perspectiva del Análisis del Discurso francés. Partimos de una filosofía de ethos basado en Maingueneau (2008a, 2008b), que se centra en el análisis del intradiscourse, es decir, formas de hablar, formas de construcción textual, los faros de la superficie discursiva. El corpus se compone de tres ediciones publicadas por la revista Capricho. Los resultados muestran los efectos de los significados (empatía,

\footnotetext{
* Doutora em Linguística e Língua Portuguesa pela UNESP-SP. Professora Adjunta IV do Departamento de Letras da UniversidadeFederal do Maranhão(UFMA). E-mail: aranha.marize@gmail.com.

** Mestrando em Letras pela Universidade Federal do Maranhão (UFMA). Licenciado em Letras pela Universidade Estadual do Maranhão (UEMA) e bacharel em Comunicação Social - Jornalismo pela UFMA. Revisor de Textos da UFMA. E-mail:claubersoncc@gmail.com
} 
espontaneidad, certeza, autoridad) establecidos en el acuerdo de comunicación firmado por esta revista, notando cómo contribuyen para la aproximación, mediante la lectura, entre enunciador periodista y receptor adolescente.

PALAVRAS CLAVE: discurso; ethos; contrato de comunicación; enunciación.

ABSTRACT: This article analyzes the formation of the ethos in the self-help discourse for teenagers from the perspective of the French School of Discourse Analysis. We start from the conception of an ethos based on Maingueneau (2008a, 2008b), who focuses on the analysis of the intradiscourse, that is, ways of speaking and ways of textual construction - landmarks of the discursive surface. The corpus comprises three editions published by Capricho (a teen-targeted magazine). The results indicate the effects of meaning (empathy, spontaneity, certainty, authority) which are established in the communication contract signed by this magazine, observing how they contribute to the development of a closer relationship between enunciator (the journalist) and enunciatee (the teenagers) by means of such text readings.

KEYWORDS: discourse; ethos; communication contract; enunciation.

\section{INTRODUÇÃOO}

Neste texto, pretendemos caracterizar o ethos do discurso de autoajuda para adolescentes, percebendo como os elementos linguísticos produzem determinados efeitos de sentidos (adesão, empatia, certeza, segurança, dúvida) nos sujeitos da enunciação. Entendemos que a comunicação humana constrói cenas, as quais modelam o discurso conforme um conjunto de estratégias pensadas no interior de um contrato de comunicação preestabelecido.

O contrato de comunicação pressupõe um acordo de reciprocidades, de práticas que nivelam as representações linguageiras dos parceiros da comunicação (CHARAUDEAU, 2010b). Tanto enunciador quanto enunciatário devem partilhar de uma competência linguageira semelhante, facilitando o efeito de adesão do discurso.

Esse efeito de adesão decorre das representações, das imagens que o enunciador faz de si e das que o enunciatário faz de seu enunciador. Isso se dá nas tramas do discurso. Daí optamos por trabalhar a noção de ethos na Análise do Discurso de orientação francesa (doravante AD), com os trabalhos de Dominique Maingueneau.

Pensamos ethos num domínio de constituição específico: o discurso de autoajuda para adolescentes. Tal domínio pretende prescrever o campo de ação dos adolescentes a partir do fornecimento de um receituário completo que abrange amplos setores da vida. Argumentamos que esse discurso se utiliza de um conjunto de saberes relacionado à adolescência, pensada enquanto fase da experiência humana, construindo o seu fio a partir de temas potenciais para esse público.

O nosso corpus compreende três edições da revista Capricho ${ }^{1}$ publicadas entre os meses de fevereiro e abril de 2014. Já as categorias analíticas focalizam a materialidade discursiva e as estratégias linguísticas empregadas, muito em virtude do nosso próprio recorte de ethos. Dessa forma, este texto está organizado em duas grandes seções: a primeira discute os conceitos que nos fundamentam ethos discursivo, contrato de comunicação, discurso de autoajuda - e a segunda apresenta a análise do corpus e a discussão dos resultados.

\footnotetext{
${ }^{1}$ Produto da Editora Abril, a revista Capricho "encontra-se em um espaço discursivo de interseção entre o feminino e o jovem", escrevendo sobre temas que "chamam atenção desse público específico” (moda, beleza, comportamento, música, sexo, horóscopo) (FRANÇA, 2013, p. 93).
} 


\section{DISCUSSÃO TEÓRICA}

Nesta seção, apresentamos uma discussão sobre os conceitos que ancoram esta análise. Partimos de uma noção de ethos que privilegia o intradiscurso - a projeção de imagem do enunciador se faz nos modos de dizer de seus enunciados; em seguida, argumentamos que os discursos fazem parte de um contrato de comunicação, com estratégias previamente pensadas; e, por fim, delineamos os domínios do discurso de autoajuda para adolescentes.

\subsection{O ETHOS DISCURSIVO}

O conceito de ethos, embora pertencente à tradição retórica ${ }^{2}$, é concebido neste trabalho no bojo de relações da AD, retomando as orientações de Dominique Maingueneau (2008a, 2008b). Justificamos nosso recorte em virtude de tal autor situar seu conceito em um quadro de análise que privilegia gêneros discursivos "instituídos", em oposição aos gêneros conversacionais. Interessam-lhe gêneros em que os sujeitos assumem papéis preestabelecidos, com certa estabilidade durante o evento comunicativo. Situação que compreende nosso objeto, a revista Capricho, na qual as posições de sujeito enunciador e sujeito enunciatário não parecem variar durante as narrativas jornalísticas.

Entendemos ethos numa perspectiva ampla, como elemento constitutivo dos discursos, no sentido de estreitar (ou não) a relação entre os sujeitos envolvidos no processo de enunciação. Estreitar a relação significa promover efeito de empatia, de adesão do coenunciador ${ }^{3}$ à posição discursiva assumida pelo enunciador quando da produção de seu discurso. Isso fica mais evidente em gêneros argumentativos, quando a adesão do coenunciador torna-se crucial para o funcionamento do gênero. Em outros gêneros, no entanto, a intencionalidade talvez não seja a de convencer, mas reivindica, demanda, de alguma forma, uma atitude do destinatário.

Para Maingueneau (2008a), ethos designa a projeção de imagem do enunciador em seu próprio enunciado, sem que, explicitamente, fale sobre si. Trata-se de um conjunto de sentidos que são atribuídos a um enunciador a partir de seu enunciado: "[...] dir-se-ia que o ethos se desdobra no registro do 'mostrado' e, eventualmente, no 'dito'. Sua eficácia decorre do fato de que envolve de alguma forma a enunciação sem ser explicitado no enunciado" (MAINGUENEAU, 2008a, p. 70). Esse conceito desenvolve-se nas margens do dito, do "aparente" no enunciado.

A noção de ethos mobiliza diretamente a percepção do coenunciador acerca da postura de seu enunciador, com o qual estabelece uma relação de sensibilidade, de afetividade nas tramas da enunciação. Há um processo interativo de influência sobre o outro. Por vezes, o coenunciador avalia o seu interlocutor antes mesmo da atitude de enunciar. Daí ser importante diferenciar ethos discursivo de ethos pré-discursivo ${ }^{4}$.

Ethos pré-discursivo recupera o conjunto de valores, crenças e saberes que são "típicos" de um enunciador que faz parte de determinado domínio discursivo. Um enunciador que profere um discurso político já carrega consigo um "posicionamento ideológico" relacionado à esfera que integra; não havendo, necessariamente, ligação direta com o seu caráter ou personalidade. $\mathrm{O}$ ethos pré-discursivo denota, portanto, representações prévias de que o coenunciador dispõe acerca de seu locutor - muito em virtude do seu lugar de fala ${ }^{5}$. Já ethos discursivo refere-se à prática de enunciação em si, situada em um marco determinado. Ambos, porém, desenham a projeção de imagem que o enunciatário tem de seu enunciador.

\footnotetext{
${ }^{2}$ Maingueneau (2008b) argumenta que o ethos no campo retórico se refere à imagem de boa impressão que o orador deseja projetar de si para convencer o auditório a que se dirige. Trata-se de um processo de convencimento.

${ }^{3}$ Neste trabalho, os termos "enunciatário", "coenunciador", "interlocutor", "público" e "destinatário" são considerados sinônimos, assim como "enunciador" e "locutor".

${ }^{4}$ Tal diferenciação fica mais evidente quando tratamos dos domínios em que cada enunciado é realizado: “[...] parece mais razoável pensar que a distinção prédiscursivo/discursivo deve levar em conta a diversidade dos gêneros de discurso" (MAINGUENEAU, 2008b, p. 60).

${ }^{5}$ Por lugar de fala entendemos o espaço institucionalizado em que as palavras assumem certas relações de sentido (de autoridade, confiança, segurança etc.) (MAINGUENEAU, 1997).
} 
Reforçamos que o ethos discursivo não se remete às características físicas ou comportamentais do enunciador (seus atributos "reais"), embora a elas esteja associado. Esse ethos mobiliza a exterioridade linguística a qual está constitutivamente na realidade intradiscursiva, nos modos de dizer. Maingueneau (2008b) chama atenção para o fato de que, além do intradiscurso, outros elementos não verbais também interferem na construção do ethos. Em um texto escrito, por exemplo, a construção doe thos perpassa as bases do linguístico, como a escolha das palavras, a força dos argumentos, a organização do texto. O ethos permanece no intradiscurso. Diferente de um texto oral, em que, além das bases linguísticas, elementos não verbais entram em cena, como mímica, tom de voz, vestimenta, postura, aparência do locutor.

Maingueneau (2008a) relaciona a projeção do "corpo do enunciador" - sem relação com o corpo do locutor extradiscursivo - a um fiador, aquele que, pelo tom de seu discurso, produz uma imagem em função das representações coletivas. Daí serem atribuídos ao fiador um caráter e uma corporalidade, os quais oscilam conforme os textos em que esse fiador aparece. Nesse cenário, o destinatário avalia o comportamento do enunciador, "apoiando-se em um conjunto difuso de representações sociais, avaliadas positiva ou negativamente, de estereótipos, que a enunciação contribui para reforçar ou transformar" (MAINGUENEAU, 2008b, p. 65).

Concebemos a incorporação do ethos discursivo numa instância maior que a realização do próprio enunciado: a cena de enunciação. Os enunciados derivam de lugares socialmente construídos, onde os sentidos circulam, ecoando certos posicionamentos acerca dos sujeitos que os assumem. Há um "mundo" associado ao interlocutor, o qual se "corporifica" a partir de cenas de enunciação. Maingueneau (2008b) propõe três cenas:

a) cena englobante: refere-se, de imediato, ao efeito pragmático do texto: discurso literário, científico, jornalístico, religioso etc., caracterizados por haver motivações pragmáticas definidas;

b) cena genérica: compreende um gênero ou subgênero do discurso, uma "instituição discursiva”, cujos limites já são conhecidos pelos enunciadores - sermão, ladainha, editorial, resenha crítica etc.;

c) cenografia: representa a cena de fala que configura certo discurso; a cenografia é demandada pelo próprio texto. A cenografia de uma notícia pode ser cômica, dramática, interativa, didática. Cada gênero constrói cenografias distintas. Há certos gêneros, porém, que não possuem cenografias, já que dispõem de formas fixas de organização - portaria administrativa, bula, atestado de óbito.

Considerando a cena enunciativa da revista Capricho, percebemos que o discurso de autoajuda aparece como elemento da cenografia então proposta. Por se tratar de um produto midiático, a cena englobante é o discurso jornalístico por excelência, cuja cena genérica compreende gêneros também jornalísticos (carta ao leitor, notícia, reportagem, comentário). A cenografia dessa revista, o modo de organização da enunciação, configura-se na autoajuda, na condução de aconselhamentos. A enunciação toma o discurso de autoajuda como cenografia narrativa, como estratégia de construção textual, considerando, claro, a projeção de imagem - o ethos - que deseja incorporar em seu público:

A cenografia, com o ethos que dela participa, implica um processo de entrelaçamento paradoxal: desde sua emergência, a fala pressupõe uma certa cena de enunciação que, de fato, se valida progressivamente por essa mesma enunciação. A cenografia é, assim, ao mesmo tempo, aquela de onde o discurso vem e aquela que dele engendra; ela legitima um enunciado que, por sua vez, deve legitimá-la, deve estabelecer que essa cena de onde a fala emerge é precisamente a cena requerida para enunciar, como convém [...] (MAINGUENEAU, 2008a, p. 77, grifos nossos).

Essa "conveniência" do enunciado, causada pela escolha da cenografia mais "adequada", decorre do contrato e das estratégias que pretende mobilizar para causar algum efeito em seu enunciatário.

\subsection{O CONTRATO DE COMUNICAÇÃO}

Entendemos contrato de comunicação como um reconhecimento recíproco das representações linguageiras pelos parceiros do momento de comunicação. Funciona como um acordo prévio, um conjunto de expectativas, de restrições que são inerentes à 
interação comunicativa. Isto é, a comunicação se constrói a partir de contratos, cuja legitimidade se fundamenta na reciprocidade de expectativas e restrições "pactuadas" entre os sujeitos do acordo (CHARAUDEAU, 2010b).

Isso porque os atos de comunicação exigem que os indivíduos conheçam previamente os dados da situação para instaurar uma interação: "[...] o sujeito comunicante sempre pode supor que o outro possui uma competência linguageira de reconhecimento análoga à sua" (CHARAUDEAU, 2010a, p. 56).

O contrato de comunicação se realiza, postula Charaudeau (2010b), por meio de dados internos e externos. Estes são constituídos no campo de uma prática social determinada, na qual os indivíduos possuem regularidades comportamentais e cujas trocas linguageiras permanecem estáveis por determinado período. Esses dados não são essencialmente linguageiros, pois envolvem comportamentos, representações de índices sociais, a condição de identidade - conjunto de traços de natureza social e psicológica que caracteriza "quem se dirige a quem". Envolve também a finalidade 6 do ato ("Estamos aqui para dizer o quê?"), o seu propósito ("Do que se trata?"), considerando o dispositivo, que representa a configuração do ato de comunicação, o quadro topológico da troca, a montagem cênica pensada de maneira estratégica ("Em que ambiente se inscreve o ato de comunicação, que lugares físicos são ocupados pelos parceiros, que canal de transmissão é utilizado?") (CHARAUDEAU, 2010b, p. 70).

Já os dados internos correspondem àqueles propriamente discursivos, relacionados ao "como dizer". Compreende "as formas verbais (ou icônicas) que devem empregar, em função das instruções contidas nas restrições situacionais" (CHARAUDEAU, 2010b, p. 70). Sinalizam, sobretudo, o conjunto de comportamentos linguageiros no ato de comunicação. Os dados internos envolvem três espaços desses comportamentos:

a) espaço de locução: espaço em que o falante justifica por que tomou a palavra ("em nome de quê?"), conquistando seu direito de poder comunicar;

b) espaço de relação: uma vez determinadas as identidades no ato de comunicação (a do locutor e a do interlocutor), são estabelecidas relações que podem ser de aliança, agressão, inclusão, neutralidade;

c) espaço de tematização: espaço onde o tema se configura a partir de forças relacionadas aos sujeitos (que trocam de assunto, ignoram ou propõem outros) e ao modo de organização discursivo particular (descritivo, narrativo, argumentativo) - isso em função das restrições situacionais.

Os dados internos e externos mobilizam um conjunto de estratégias na cena comunicativa posta em evidência. Consideramos estratégia dentro do escopo da enunciação, em que o enunciador organiza e encena suas intenções a fim de produzir algum efeito sobre o enunciatário (CHARAUDEAU, 2010a).

O ethos discursivo, portanto, constitui-se nas redes de sentido das diversas cenas enunciativas formuladas pela comunicação humana. À medida que o sujeito conduz seu discurso, inevitavelmente deixa marcas que o denunciam enquanto enunciador. Falamos, de forma mais específica, em pistas linguísticas, expostas na superfície de análise, reveladoras de posições ou alternância de posições típicas da instabilidade dessas cenas enunciativas.

\subsection{O DISCURSO DE AUTOAJUDA (PARA ADOLESCENTES)}

Entendemos o discurso de autoajuda como um conjunto de ideias que orientam os leitores em relação à descoberta, ao cultivo e ao emprego de seus "recursos interiores para a realização de todos os seus desejos e sonhos" (CHAGAS, 2002, p. 85).

\footnotetext{
${ }^{6}$ Charaudeau (2010b) elenca quatro tipos de visada, que podem agir de forma articulada: a prescritiva, que consiste em influenciar o outro a agir de determinada forma, "fazer fazer"; a informativa, que pretende passar um saber a quem se presume não sabê-lo, "fazer saber"; a incitativa, que leva o outro a acreditar no efeito de verdade do que é dito, "fazer crer"; e a visado do pathos, cujo objetivo é promover no outro algum sentimento, um estado emocional, "fazer sentir".
} 
Ao classificar a literatura de autoajuda, o pesquisador Arnaldo Chagas (2002, p. 89) utiliza a orientação de Tania Salem (1992), que a organiza em duas vertentes?

a) vertente psicológica: os livros abrangem conceitos da Psicologia e da Psicanálise, propondo "soluções" e "alternativas" para o homem conviver em sociedade. Destacam-se as temáticas sobre amizade, relacionamento, temperamento, qualidade, defeitos, dificuldades, superação, autoestima, entre outros;

b) vertente esotérica: estimula as potencialidades mentais, o aperfeiçoamento espiritual do sujeito, visando à paz e ao equilíbrio. A ideia é ensinar o leitor a potencializar os poderes da mente.

Houve uma expansão da crença no poder da mente, isto é, a literatura de autoajuda passou a se firmar na pretensão de "otimização do poder mental". Os autores, então, produziram manuais, guias que descreviam técnicas e métodos para auxiliar o leitor no domínio sobre si mesmo por meio do pensamento. $\mathrm{O}$ autodomínio estava condicionado ao controle do pensamento.

Segundo Chagas (2002, p. 91), os chamados manuais "mentalistas" se fundamentavam nas crenças da filosofia espiritual e na sabedoria oculta das sociedades antigas. Acrescentavam, também, elementos extraídos das religiões, da tradição esotérica e da psicologia subliminar do eu.

Os manuais mentalistas constroem "receitas" para cultivo e aprimoramento das faculdades mentais, apresentando técnicas para serem aplicadas em tarefas do dia a dia. Isto é, os autores legitimam tais receitas nos apontamentos clássicos, esotéricos, religiosos e propõem a aplicação desses ensinamentos na vida do leitor. Para esses manuais, o sofrimento, por exemplo, corresponde à má utilização da mente.

Não interessa aos leitores conhecer o funcionamento, os mecanismos ou a natureza da mente, mas apenas saber usá-los. A ideia é "tudo vai funcionar bem se a mente vai bem". A mente funciona como elemento independente, autônomo e responsável por todas as atitudes e consequências na vida do sujeito.

A função da literatura de autoajuda está na solução de problemas individuais. Segundo Rüdiger (1996, p. 85), essa literatura trabalha com remédios supramorais, que "tratam" as preocupações do indivíduo em relação à percepção social de um conflito ligado à própria personalidade.

Pensar o discurso de autoajuda para adolescentes sob essa perspectiva significa problematizar a natureza do enunciatário adolescente na cena enunciativa para ele elaborada. Entram em jogo as especificidades dessa fase da experiência humana que constitui um período de transição, transformação biológica, psicológica e sociocultural. Esse momento de transição carrega um conjunto de elementos temáticos que vão construir o fio do discurso, como, por exemplo, sentimento de incompletude, crise de identidade e necessidade de aceitação; envolvendo também estratégias de narrativa específicas: textos narrados em primeira pessoa; história de vida em que o sujeito relata a descoberta de suas forças mais íntimas e a maneira como as empregou para superar seus problemas individuais; ou narra como passou por um processo de mudança interior, tornando-se uma pessoa mais feliz (FORNARI; SOUZA, 2001, p. 134).

Nesse cenário, a adolescência configura-se, sobretudo, como "uma etapa marcada por tormentos e conturbações vinculadas à emergência da sexualidade" (BOCK, 2007, p. 64). De um lado, estão os conflitos relacionados a uma crise existencial; do outro, os relacionados ao amadurecimento do corpo. A fase da adolescência relaciona "problemas" que partem do desenvolvimento biológico e chegam ao nível existencial, criando redes de crise identitária bastante frequentes e intensas.

Não entendemos crise numa acepção pejorativa, como estado de distúrbio ou de doença, mas como um momento de decisão, de escolha, em que o indivíduo precisa optar por uma ou outra direção. Trata-se, na verdade, de uma situação de disputa, de tensão, de

${ }^{7}$ Reforçamos que essa classificação não é rígida: há livros de autoajuda que utilizam elementos das duas vertentes. Essa classificação tenta separar os títulos que frisam mais o sujeito nas relações sociais e os que se apegam aos poderes da mente. 
conflito, que mobiliza, segundo Erik Erikson (1976), recursos de crescimento, recuperação e diferenciação. Enquanto crise de identidade designa, segundo o mesmo autor, a perda da noção de identidade pessoal e de continuidade histórica, isto é, perda do controle sobre si próprio, potencializada ainda mais na fase da adolescência.

Por isso, quando especificamos o público para o qual esse discurso se dirige, defendemos o argumento de que todo discurso é orientado (MAINGUENEAU, 2013). Não há discurso sem endereçamento, mesmo que o enunciatário seja imaginário, virtual ou indefinido. Ainda que de forma imaginária, o sujeito cria projeções de seu enunciatário, modelando o discurso conforme um conjunto de expectativas que julga decisivo para criar nele algum efeito - momento de constituição de seu ethos.

\section{ANÁLISE DO CORPUS E DISCUSSÃO DOS RESULTADOS}

Nesta seção, procedemos à análise do corpus $^{8}$, a fim de identificar como se constitui o ethos do discurso de autoajuda para adolescentes. Privilegiamos duas categorias de análise: os marcadores conversacionais e a modalidade linguística. Isso em virtude da regularidade (recorrência nos textos) e da produtividade (em termos de discussão) das marcas linguísticas no material analisado.

Figura 1: Capas das edições 1195, 1196 e 1197
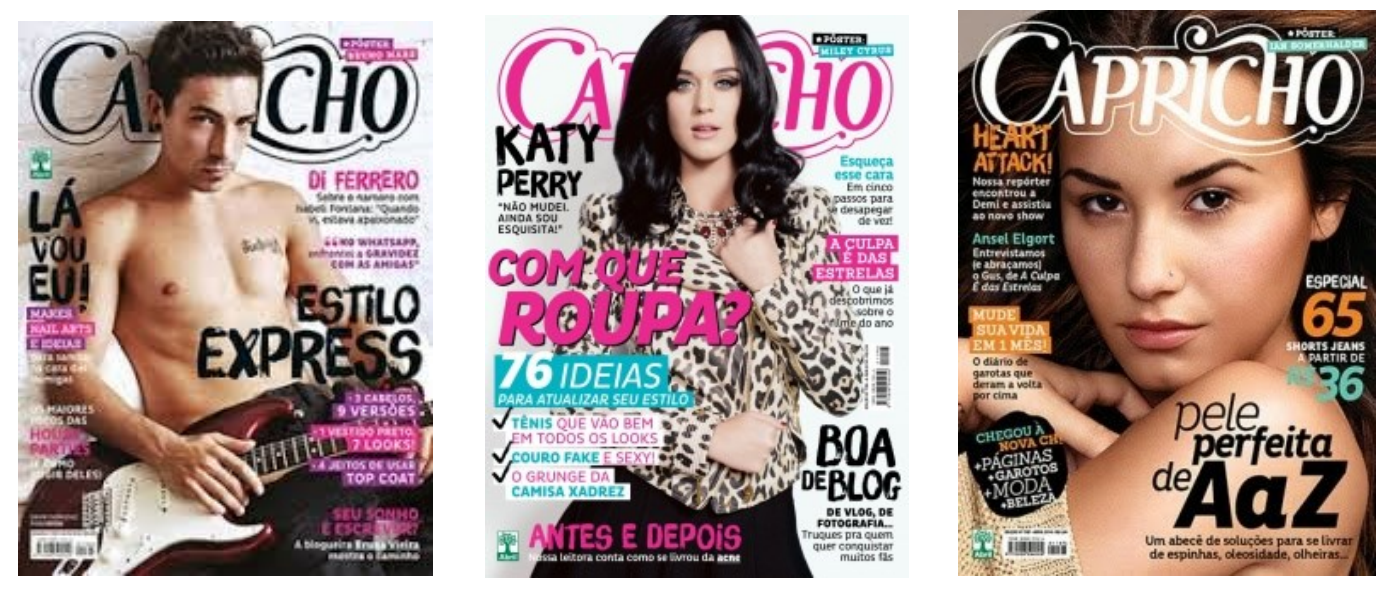

\subsection{OS MARCADORES CONVERSACIONAIS}

Situamos os marcadores conversacionais (MC, doravante) nos trabalhos de Marcuschi (2003), que os define como elementos do texto conversacional que operam tanto no nível comunicativo (no fluxo da comunicação) quanto na organização sintática (na disposição estrutural das informações). Pensamos nessa categoria analítica em virtude de o texto da revista Capricho apresentar-se repleto de marcas de oralidade, isto é, um texto muito próximo à fala. E isso designa mais do que processos de construção textual. Denota estratégias que visam promover efeitos de empatia entre enunciador jornalista e enunciatário adolescente. Como consequência, as "barreiras" entre esses sujeitos da enunciação se tornam menos rígidas e mais difusas.

Marcuschi (2003) classifica os MC do tipo recursos verbais ${ }^{9} \mathrm{em}$ sinais pré-posicionados e pós-posicionados.

\footnotetext{
${ }^{8}$ Selecionamos para análise apenas enunciados em que notamos claro tom de autoajuda. Nesse sentido, as editoriais de moda, música e celebridade, por exemplo, não foram focadas, enquanto as de comportamento, sexo e horóscopo reclamaram nosso olhar - isso em virtude da delimitação aqui definida.

${ }^{9}$ Marcuschi (2003) argumenta que os marcadores conversacionais se estruturam em recursos verbais (por expressões linguísticas), recursos não verbais (olhar, riso, gesticulação) e suprassegmentais (pausas e tom de voz). Como nosso material de análise pertence ao suporte impresso, privilegiamos os recursos verbais.
} 
a) sinais pré-posicionados: são utilizados no início do turno ou da unidade comunicativa. Normalmente, eles demarcam o turno de fala do enunciador ou o encadeamento do tópico tratado.

(1) Ok, você já ouviu falar muito sobre ela. Afinal, é adolescente, e nessa fase, os hormônios enlouquecem. E o que isso tem a ver com os cravos e as espinhas que teimam em aparecer? É que alguns desses hormônios estimulam a produção de sebo pelas glândulas sebáceas, responsáveis pela oleosidade da pele. (PARCA, 2014, p. 43, grifo nosso)

(2) Em 2012, a blogueira do Depois dos Quinze saiu da casa da mãe, em Leopoldina (MG), para se jogar em São Paulo e, desde lá, adora conhecer os cantos bonitinhos da cidade. Foi pensando nisso que decidi levá-la à minha doceria preferida: a Brigadeiro Café, em Pinheiros. [...] Chegando lá, ainda deixaram a gente fazer o tal do brigadeiro na cozinha! Bom, foi aí que descobri algo novo sobre a Bru: assim como eu, ela não sabe cozinhar! [...]. (CATANIA, 2014, p. 22, grifos nossos)

(3) Sim, os xampus para os cabelos oleosos são feitos para você. Mas, se usados em excesso, podem causar o efeito rebote, ou seja, fios ainda mais oleosos. Por isso, alterne o xampu específico com outro para cabelos normais, qualquer um de que você goste. (OIL, 2014, p. 43, grifo nosso)

(4) Não se esqueça de hidratar o corpo e beba água o tempo todo! Você pode nem perceber, mas isso fará diferença. Ah: se não gostar de academia, encontre alguma atividade física que combine com você. Pode ser bem diferente, tipo patinação. Quem sabe? Experimente e cuide do seu corpo e da sua saúde! (MARTINS, 2014, p. 87 , grifo nosso)

Nos exemplos acima, os marcadores conversacionais em negrito representam sinais pré-posicionados, isto é, recursos linguísticos que iniciam o turno de fala (neste caso, o parágrafo) ou favorecem a progressão dos tópicos tratados (função de sequência textual). Para além dessas funções, os marcadores promovem determinados efeitos de sentido, sobretudo relacionados à interação verbal. Nesse aspecto, dialogamos com os trabalhos de Guerra (2007) e Furlan (2013), que, apesar de utilizarem o termo marcadores discursivos, estudam elementos de natureza semelhante aos que abordaremos aqui.

Em (1), ok assume função clara de reforçar a interação. Em termos de conversação, há o efeito de que algo já foi dito antes, um saber presumido, compartilhado entre os enunciadores. Guerra (2007) atribui a esse marcador função de sequenciamento interativo do tipo iniciador. Ele reforça um efeito de espontaneidade do texto, construindo uma cena de intimidade, típica de relação afetuosa de amizade. Os MC favorecem a construção de uma cena enunciativa mais descontraída, cujo texto parece estar mais próximo da fala do que da escrita. Trata-se claramente de uma estratégia discursiva empregada por um sujeito que conhece o funcionamento do contrato de comunicação aí vigente.

O mesmo parece acontecer em (3), quando o enunciador inicia seu turno de fala com sim. Esse MC sinaliza, novamente, um préconstruído ${ }^{10}$ relacionado à adolescência - fase em que há potencial produção de hormônios afetando, por exemplo, a oleosidade dos cabelos. Ao utilizar sim, o sujeito enunciador projeta a imagem de quem conhece muito bem essa fase, antecipando, de imediato, que o tópico de que irá tratar é decisivo para a adolescente. O MC sim promove um efeito de certeza à enunciação, como se o sujeito enunciador detivesse autoridade para falar sobre o assunto.

Em (2), o MC bom, foi aí desempenha função essencialmente textual. Como se trata de uma narrativa de autoajuda, a ideia é tornála mais "fluente" possível, isto é, a narrativa se constrói de modo semelhante às narrativas orais (a conversação), cujos operadores coesivos se diferem em parte dos operadores do texto escrito. Assim como em (1), o MC denota um efeito de espontaneidade, porém mais relacionado à progressão dos enunciados.

\footnotetext{
${ }^{10}$ Para Maingueneau (1998, p. 114), o pré-construído integra "certos enunciados anteriores mantidos no interior da mesma formação discursiva ou numa formação adversa”.
} 
Em (4), observamos o MC ah. Este uso potencializa ainda mais o efeito de que o texto possui mais traços da língua falada do que da língua escrita. Isso porque $a h$ reflete um efeito de hesitação: é como se o sujeito enunciador se esquecesse de mencionar algo e, ao lembrar, recupera o turno para tratar do tópico "esquecido". A hesitação é característica determinante do texto falado informal, em que "há uma interrupção no fluxo informacional devido a uma má seleção futura, resultando em um enunciado ainda não concluído" (FÁVERO; ANDRADE; AQUINO, 2012, p. 60). No texto escrito, a hesitação pode ser suprimida com a simples reescrita do texto, sem que isso seja perceptível. No enunciado (4), o sujeito enunciador faz questão de demonstrá-la, a fim de reforçar o efeito de espontaneidade exigido pelo contrato de comunicação estabelecido na/pela revista Capricho.

b) sinais pós-posicionados: Marcuschi (2003, p. 68) orienta que os sinais pós-posicionados estão situados no final do turno de fala ou na conclusão de um subtópico.

(5) Vênus entra no seu signo e, com isso, começa uma nova fase na sua vida e no amor. Você deve se sentir mais ousada, com coragem para arriscar, viver coisas novas e ir além do óbvio. [...] Se você estiver solteira, aproveite e não fique dentro de casa sem fazer nada! E os meninos vão te perceber de longe, viu? Pronta para brilhar muito, aquariana?(MARTINS, 2014, p. 87, grifo nosso)

(6) O garoto de Sagitário: ele deverá colar nos amigos como nunca e, como consequência, se interessar por meninas da turma ou que ele conheça por meio da galera. Já sabe o que fazer, né? Boa sorte! (CAPRICHO, ed. 1196, 2014, p. 86, grifo nosso).(MARTINS, 2014, p. 86, grifo nosso)

(7) Eu e minha irmã nos odiamos por boa parte da adolescência - assaltos ao guarda-roupa tiveram muito a ver com isso -, mas hoje somos amigas. É que vivendo sob o mesmo teto vocês disputam espaço físico, atenção dos pais, grana pra sair etc. Normal rolar uma rivalidade. Só não deixa abusar disso. E lembre que, se sua irmã é agressiva, é porque também tem as inseguranças dela. Afinal, você é a que fala inglês, né? [...] (ARAÚJO, 2014, p. 74, grifo nosso)

(8) Vou fazer um book! E agora? Calma, amiga, chegamos! Strike a pose. Melhor presente ever: o amigo da Dayane Mendes, 15 anos, vai dar um book de presente para ela. Maravilhoso, né? Mas... e aí, que roupar usar? Calma, Day, a gente te ajuda! (LOOK, 2014, p. 63, grifos nossos)

Nos exemplos acima, encontramos MC com duas funções específicas: feedback e checking, ambas voltadas à interação. Os marcadores com função de feedback "expressam uma nítida orientação por parte do ouvinte em relação ao falante, através da manifestação de um acompanhamento atencioso da fala do outro" (GUERRA, 2007, p. 62). Já os com função de checking "expressam nítida orientação por parte do falante em direção ao ouvinte, através da busca de uma aprovação discursiva” (GUERRA, 2007, p. 62). Em outras palavras, enquanto estes buscam uma aprovação em relação ao tópico tratado, aqueles estão orientados para o prosseguimento da conversação, para checar a atenção do interlocutor.

Nos enunciados (5) e (8), os MC viu? e e aí exercem a função de feedback, pois estão mais orientados a perceber se o leitor está de fato acompanhando a narração. Em (5), o sujeito enunciador constrói uma cena clara de autoajuda, traçando conselhos amorosos à leitora da revista. O MC viu? aparece como sustentador do tópico tratado, uma espécie de "cobrança” de atitude do enunciatário adolescente, que precisa "ir além do óbvio". Em (8), o MC e aí também exerce a função de antecipar uma possível pergunta desse enunciatário.

Em (6), (7) e (8) o MC né expressa a função de checking. No nosso corpus, esse MC aparece com bastante regularidade; é o principal marcador, o que nos permite inferir que o sujeito enunciador da revista Capricho busca, constantemente, a aprovação do interlocutor em relação aos enunciados. O né é mais um elemento que constrói a cena de espontaneidade, de intimidade entre os sujeitos do contrato de comunicação. Isso fica evidente nas pistas linguísticas materializadas nos enunciados as quais revelam um sujeito menos jornalista e mais adolescente, percepção também defendida por Mira (2001, p. 78), segundo a qual a revista passa a ocupar o lugar de irmã ou amiga da leitora, "conversando sobre os seus problemas mais íntimos". 
Em pesquisa semelhante, Furlan (2013) também constatou que o discurso de autoajuda para adolescente constrói uma cena mais espontânea, menos rígida, diferentemente do discurso de autoajuda tradicional, em que o sujeito enunciador se posiciona como dono da verdade e do saber. Quando o enunciatário é um adolescente, a tessitura do discurso se modela de forma a atenuar o caráter de autoridade que é inerente à literatura de autoajuda. E essa forma de atenuar se manifesta a partir de marcas linguísticas. Como consequência, o sujeito enunciador encena ser "amigo" da adolescente, com quem pode conversar, sem restrições, sobre qualquer tema:

As ocorrências dos marcadores discursivos interacionais, que indicam uma relação mais direta entre os interlocutores, ou seja, pelos quais os interlocutores se dirigem um ao outro de maneira mais próxima ou íntima, representam, linguisticamente, uma cena de interação próxima entre os enunciadores, mais propriamente um diálogo, o que imprime ao texto um tom mais informal, próprio desse tipo de interação (FURLAN, 2013, p. 62).

\subsection{A MODALIDADE LINGUÍSTICA}

Ao eleger a categoria modalidade para a análise do nosso corpus, pretendemos verificar como se manifesta a relação de certeza ou de dúvida do enunciador sobre o seu enunciado. O nosso interesse é perceber se o discurso de autoajuda para adolescentes manifesta graus de certeza sobre aquilo que diz.

O conceito de modalidade não tem bases consensuais bem definidas. Por isso, nosso estudo fundamenta-se nas acepções propostas por Neves (2011, 2002), Brunelli (2004) e Brunelli e Dall'Aglio-Hattnher (2011), que focalizam a natureza estrutural (a forma linguística) e os efeitos de sentidos que se realizam no processo de comunicação.

Nessa perspectiva, por modalidade entendemos um conjunto de relações entre enunciador, enunciado e realidade objetiva, em que o enunciador demarca, de algum modo, termos de verdade e certos graus de certeza no que expressa (NEVES, 2011). Em outras palavras, é possível perceber em enunciados o modo de relação do enunciador sobre o estado das coisas, ou o julgamento do falante sobre a probabilidade de ser verdadeiro o enunciado por ele expresso.

Em nossa pesquisa, utilizamos a noção de modalidade relacionada à expressão de necessidade e de possibilidade, a saber: modalidades deôntica e epistêmica. Isso em virtude do propósito do discurso de autoajuda, que se organiza no campo do aconselhamento - e, em consequência, impõe necessidades e possibilidades de ser/fazer algo ${ }^{11}$.

\subsubsection{A modalidade deôntica}

Esta modalidade relaciona-se "aos valores de permissão, obrigação e volição" (NEVES, 2002, p. 180). Realiza-se por traços ligados ao enunciador, que demonstra ter ou não controle do que diz, e ao enunciatário, que pode aceitar ou não o valor de verdade do enunciado para executá-lo. Trata-se da instauração de deveres, de eixos de conduta, os quais são orientados de duas maneiras:

a) para o participante:

(9) Mania de limpeza. Você precisa saber uma coisa sobre sua higiene íntima: a fixação em deixar a vulva sempre cheirosíssima e brilhando pode acabar destruindo a flora natural da região, abrindo caminho para infecções. Claro que higiene é importante, mas não exagere [...](BESSA, 2014, p. 54, grifos nossos)

(10) O vestibular está chegando e não consigo dormir. Não aguento a pressão dos pais, da escola e a pressão que eu ponho em mim. I.V., 17 anos I. Essa fase é difícil mesmo. Mas umas duas horinhas de relax por dia não vão

\footnotetext{
${ }^{11}$ A nossa escolha também se justifica pela própria natureza dos tipos de modalidade. Segundo Neves (2002, p. 180-181), as modalidades epistêmica e deôntica constituem a modalização linguística stricto sensu, ou seja, "a modalização ocorrente e analisável nos enunciados efetivamente produzidos".
} 
prejudicar seu desempenho. Procure fazer o que gosta nesse tempo. Ele vai lhe dar mais pique para estudar! (ARAÚJO, 2014, p. 103, grifos nossos)

(11) Olha, M., não dá para apagar o que já foi. É natural que as pessoas ainda se lembrem e comentem coisas que fez há tempos. Mas não seja dura consigo mesma, afinal, todo mundo comete erros. Dê tempo ao tempo. Suas ações, aos poucos, vão substituindo o seu "currículo". Quando comentarem, faça a celeb. Com cara de paisagem, diga que tudo é coisa do passado... (ARAÚJO, 2014, p. 103, grifos nossos)

Em (9), (10) e (11), o sujeito enunciador se utiliza de qualificadores deônticos para imprimir um efeito de autoridade ao que diz. Esses qualificadores "funcionam sempre como instrumentos à disposição do enunciador para impor vontades sobre o enunciatário" (BRUNELLI; DALL'AGLIO-HATTNHER, 2011, p. 22). De forma explícita, estão orientados, pois, ao participante, regulando-lhes o comportamento por meio de ordens e proibições.

Nos enunciados em destaque, a modalização deôntica se estabelece por meio de verbos auxiliares ("precisa saber", "procure fazer", "não dá para apagar") e de verbos no modo imperativo, como destacado em (11). Essas construções também contribuem para a manifestação de certeza, caracterizando o ethos do discurso de autoajuda para adolescentes, no qual o sujeito aconselhador precisa projetar uma imagem de quem domina o que diz:

Como se trata de uma questão de acreditar, de não duvidar, entendemos que os autores de auto-ajuda, enquanto sujeitos desse discurso, também devem manifestar em seus textos, com relação às teses que propõem, essa mesma crença/confiança que pregam para os seus leitores. Além disso, se as teses que apresentam são verdadeiras, se as fórmulas e orientações propostas efetivamente funcionam e se tudo é realmente uma questão de acreditar, então a incerteza e a dúvida devem mesmo ser manifestações excluídas e ou rejeitadas nos textos desse discurso (BRUNELLI, 2004, p. 8, grifos nossos).

b) para o evento:

(12) Posso machucar a vagina durante o sexo? O canal vaginal é um tecido tão, mas tão resistente que é praticamente impossível ele sair ferido de uma transa. É claro que, se você fizer uso de algum objeto que não seja indicado para isso, pode acabar sofrendo alguma lesão (ei, vale aqui a mesma dica da masturbação). Também não é possível "quebrar" a vagina durante o sexo. Não é raro encontrarmos pessoas com esse tipo de insegurança, mas não encana: isso é mito! É verdade que, dependendo da posição ou do tamanho do pênis, é possível, sim, sentir um leve incômodo no colo do útero, mas nada que possa feri-lo de forma mais séria. Ufa! (MACHUCAR..., 2014, p. 95, grifos nossos)

(13) Se você já consegue se imaginar com outros: quando você está realmente desencanada, é fácil se imaginar pegando o gato da praia (e namorando com ele!). Assim, sem nenhuma culpa ou vontade de estar com o ex. (ARAÚJO, 2014, p. 94, grifos nossos)

Em (12) e (13), os valores deônticos não estão focalizados diretamente no enunciatário. O sujeito enunciador expressa a manifestação de dever a partir de adjetivos em posição predicativa, recaindo o potencial deôntico sobre o evento. Assim como os adjetivos, os verbos no infinitivo suavizam o caráter de obrigação dos enunciados, atribuindo-lhes um efeito de impessoalidade, quando, na verdade, a instauração de dever permanece demarcada, porém com mecanismos de atenuação. A modalidade deôntica orientada para o evento tenta apagar o valor de imposição dos enunciados.

Além disso, em (12), visando atenuar seu papel de fonte instauradora da obrigação, o sujeito enunciador se inclui no enunciado: "Não é raro encontrarmos pessoas com esse tipo de insegurança". Tal opção configura clara estratégia de envolvimento, de aproximação com o participante. Não se trata de impor uma obrigação a alguém, mas de se incluir no grupo dos que necessitam de um conselho. Há uma neutralização momentânea da posição hierarquicamente superior da fonte deôntica (BRUNELLI; DALL'AGLIO-HATTNHER, 2011). 


\subsubsection{A modalidade epistêmica}

Esta modalidade relaciona-se com a necessidade e a possibilidade epistêmicas; refere-se ao eixo da crença; "envolve os seguintes conceitos: certo, provável, contestável e excluído" (BRUNELLI, 2004, p. 14). Trata-se de o enunciador revelar o grau de possibilidade de determinando evento acontecer, podendo ou não expressar comprometimento em relação ao conteúdo do enunciado. Ocorre também de duas formas:

a) para o evento:

(14) Se você já consegue se imaginar com outros: quando você está realmente desencanada, é fácil se imaginar pegando o gato da praia (e namorando com ele!). Assim, sem nenhuma culpa ou vontade de estar com o ex. (ARAÚJO, 2014, p. 94, grifos nossos)

(15) Bom a primeira vezé a parte da história de cada uma, não existe uma primeira vez única! Isso vale tanto para a emoção do momento quanto para esses detalhes técnicos que devem estar lhe incomodando. Pode doer, pode sangrar, pode ser rápido e... pode ser o inverso de tudo isso! Você também pode sentir prazer logo de cara ou nem tanto assim [...] (ARAÚJO, 2014, p. 101, grifos nossos)

Em (14) e (15), os modais epistêmicos estão orientados para a possibilidade de um evento ocorrer. Em (14), o sujeito enunciador arquiteta possíveis cenários, traça exemplos que balizam o poder argumentativo de seus enunciados. Isso promove um efeito de distanciamento, pois condiciona ao próprio evento a probabilidade de este ocorrer, e não ao juízo de valor do sujeito enunciador. Gera também um efeito de dúvida ao dito, não comprometendo, porém, o caráter de autoridade do discurso de autoajuda, como bem argumentam Brunelli e Dall'Aglio-Hattnher (2011, p. 25): “[... embora as ocorrências em questão sejam manifestações de possibilidade, elas não se apresentam como manifestações de incerteza do sujeito enunciador em si, que se esquiva desse comprometimento [...]".

Em (15), o modal pode é recorrente, corroborando o argumento de que os eventos estão no plano da possibilidade. Trata-se de não conferir um tom taxativo a eventos que designam situações as quais os adolescentes podem vivenciar. O efeito de incerteza não está sobre o enunciado (o conteúdo em si), mas sobre as situações que envolvem os enunciatários. Assim como em (14), o sujeito enunciador parece não emitir um juízo de valor em seus enunciados, esquivando-se de possíveis comprometimentos em relação às avaliações/conselhos que propõe, ou seja, a manifestação de possibilidade o isenta da responsabilidade pelos eventos que narra.

b) para a proposição:

(16) Tranks, sempre. Sua terceira questão é quase existencial, né? Vocêtem medo de ser uma garota fácil. Aí, vou perguntar: fácil para quem? A única pessoa que pode julgá-la é você mesma. Agora, imaginando que seu ex pense assim, você quer mesmo estar perto de um garoto que não valorize? Sai dessa! Também não acho que seja fácil, mas se isso é uma preocupação, é possível que você não esteja preparada para levar a vida de um jeito mais ousado, né? (risos) [...](ARAÚJO, 2014, p. 94, grifos nossos)

(17) D., infelizmente, ainda há pais que são mais protetores com as filhas. Mas dá para virar esse jogo conversando com eles. [...] (ARAÚJO, 2014, p. 100, grifo nosso)

Já em (16) e (17) a qualificação epistêmica recai sobre a proposição, revelando graus de envolvimento do sujeito enunciador com o enunciado. Em (16), o sujeito, categoricamente, se envolve na narrativa (com a emergência da forma verbal acho), manifestando seu juízo de valor no conselho dado, enquanto em (17) o advérbio modalizador infelizmente denuncia a posição de comprometimento.

Apesar de ainda estar no plano do possível, o sujeito enunciador não parece titubear, muito em virtude do contrato de comunicação firmado nesse plano: como o ethos do discurso de autoajuda manifesta potenciais efeitos de certeza, o eixo de dúvida, mesmo em 
situações de possibilidade, reveste-se de valores de verdade. Em outras palavras, o tom de autoajuda encenado pela revista Capricho constrói um ethos de certeza/verdade tão forte que até o efeito de possibilidade se reconfigura num sujeito enunciador bastante convicto do que diz.

\section{CONSIDERAÇÕES FINAIS}

Neste texto, analisamos o ethos do discurso de autoajuda para adolescentes. Escolhemos como corpus três edições da revista Capricho, uma das principais publicações brasileiras com foco no universo jovem. Nossa intenção foi identificar as bases linguísticas que caracterizam os modos de dizer desse tipo de discurso, entendendo-as num plano maior (o discursivo), a fim de perceber quais efeitos de sentido as escolhas linguísticas manifestam.

Situamos as questões da língua no escopo do contrato de comunicação. Isso significa dizer que a comunicação humana se realiza por meio de contratos, que exigem certas regularidades em termos de estrutura linguística, como forma de criar efeitos de adesão no seu público potencial. Atribuímos às escolhas linguísticas o caráter de estratégia, de forma a negar qualquer hipótese que pressupõe a construção de enunciados como fruto de uma causalidade.

A nossa visada privilegiou duas categorias de análise: os marcadores conversacionais e a modalidade linguística. Elas apontaram que o ethos do discurso de autoajuda para adolescentes reclama, de um lado, efeitos de espontaneidade, em busca do envolvimento com o enunciatário; e, de outro, efeitos de autoridade, na manifestação de certeza que caracteriza o seu domínio.

\section{REFERÊNCIAS}

ARAÚJO, Mariana. Gêmea versus gêmea. Revista Capricho, São Paulo, ed. 1195, p. 74, fev. 2014.

. As 54 dúvidas que elas adoram perguntar. Revista Capricho, São Paulo, ed. 1197, p. 98-103, abr. 2014.

. Quando o ex vira peguete. Revista Capricho, São Paulo, ed. 1197, p. 94, abr. 2014.

BESSA, Marina. Repita comigo: va-gi-na. Revista Capricho, São Paulo, ed. 1197, p. 54-55, abr. 2014.

BOCK, Ana Mercês Bahia. A adolescência como construção social: estudo sobre livros destinados a pais e educadores. Psicol. esc. educ., jun. 2007, v.11, n. 1, p. 63-76.

BRUNELLI, Anna Flora. O sucesso está em suas mãos: análise do discurso de auto-ajuda. 2004. 149f. Tese (Doutorado em Linguística) - Instituto de Estudos da Linguagem, Universidade Estadual de Campinas, Campinas, 2004.

BRUNELLI, Anna Flora; DALL'AGLIO-HATTNHER, Marize Mattos. As qualificações do saber, do dever e do poder: uma análise linguística do discurso de autoajuda. In: BARONAS, Roberto Leiser; MIOTELLO, Valdemir (Org.). Análise de discurso: teorizações e métodos. São Carlos: Pedro \& João Editores, 2011.p. 13-31.

CATANIA, Fernanda. A vida é doce. Revista Capricho, São Paulo, ed. 1197, p. 22, abr. 2014.

CHAGAS, Arnaldo. O sujeito imaginário no discurso de auto-ajuda. Ijuí: Ed. Unjuí, 2002.

CHARAUDEAU, Patrick. Linguagem e discurso: modos de organização. 2. ed. São Paulo: Contexto, 2010a.

Aranha \&Carvalhol "Pronta parabrilhar muito, aquariana?"; o ethos do discurso de autoajuda para adolescentes 
CHARAUDEAU, Patrick. Discurso das mídias. São Paulo: Contexto, 2010b.

ERICKSON, E. Identidade, juventude e crise. Rio de Janeiro: Zahar, 1976.

FÁVERO, Leonor Lopes; ANDRADE, Maria Lúcia da Cunha V. de Oliveira; AQUINO, Zilda Gaspar Oliveira de. Oralidade e escrita: perspectivas para o ensino de língua materna. 8. ed. São Paulo: Cortez, 2012.

FORNARI, Liege Maria Sitja; SOUZA; Elizeu Clementino de. As narrativas nos discursos de auto-ajuda. Revista da FAEEBA, Salvador, n. 15, p. 133-141, jan./jun., 2001.

FRANÇA, Renné Oliveira. Revista e referentes: a pensata na construção do mundo de cada publicação. In: TAVARES, Frederico de Mello B.; SCHWAAB; Reges (Org). A revista e seu jornalismo. Porto Alegre: Penso, 2013. p. 93-106.

FURLAN, Marília Molina. Cenas de enunciação e ethos discursivo: análise do discurso de autoajuda para adolescentes. 2013. 162f. Dissertação (Mestrado em Letras) - Universidade Estadual Paulista Júlio de Mesquita Filho, Campus de São José do Rio Preto, 2013.

GUERRA, A. R. Funções textual-interativas dos marcadores discursivos. 2007. 233f. Dissertação (Mestrado em Estudos Linguísticos) - Instituto de Biociências, Letras e Ciências Exatas, Universidade Estadual Paulista Júlio de Mesquita Filho, São José do Rio Preto, 2007.

LOOK para o book. Revista Capricho, São Paulo, ed. 1195, p. 63, fev. 2014.

MACHUCAR não pode. Revista Capricho, São Paulo, ed. 1197, p. 95, abr. 2014.

MAINGUENEAU, Dominique. Ethos, cenografia, incorporação. In: AMOSSY, R. (Org.). Imagens de si no discurso: a construção do ethos. São Paulo: Contexto, 2008a. p. 69-92).

Cenas da enunciação. Parábola Editorial: São Paulo, 2008b.

. Análise de textos de comunicação. Tradução de Maria Cecília P. de Souza-e-Silva. 6. ed. ampl. São Paulo: Cortez, 2013.

. Novas tendências em análise do discurso. 3. ed. Campinas: Pontes, 1997.

. Termos-chave da análise do discurso. Tradução de Márcio Venício Barbosa e Maria Emília Amarante Torres Lima. Belo Horizonte: Ed. UFMG, 1998.

MARCUSCHI, Luiz Antônio. Análise da conversação. 5. ed. São Paulo: Editora Ática, 2003.

MARTINS, Luciana. Horóscopo. Revista Capricho, São Paulo, ed. 1195, p. 86-87, fev. 2014.

. Horóscopo. Revista Capricho, São Paulo, ed. 1196, p. 86-87, mar. 2014.

MIRA, Maria Celeste. O leitor e a banca de revistas: a segmentação da cultura no século XX. São Paulo: Fapesp, 2001.

NEVES, Maria Helena de Moura. A modalidade. In: KOCH, Ingedore G. Villaça (Org.). Gramática do português falado. V. VI: Desenvolvimentos. 2. ed. rev. Campinas: Editora da UNICAMP, 2002. p. 171-204.

NEVES, Maria Helena de Moura..Imprimir marcas no enunciado. In: Texto e gramática. São Paulo: Contexto, 2011. 
OIL free. Revista Capricho, São Paulo, ed. 1195, p. 43, fev. 2014.

PARCA, Giulia. Pele linda de A a Z. Revista Capricho, São Paulo, ed. 1197, p. 42-47, abr. 2014.

RÜDIGER, Francisco. Literatura de auto-ajuda e individualismo. Porto Alegre: Ed. UFGRS, 1996.

Recebido em 1\%/10/2015. Aceito em 31/10/2015. 